Article

\title{
Some Observations on the Development of Superior Photocatalytic Systems for Application to Water Purification by the "Adsorb and Shuttle" or the Interphase Charge Transfer Mechanisms
}

\section{Cooper Langford ${ }^{1, *}$, Maryam Izadifard ${ }^{2, \dagger}$, Emad Radwan ${ }^{3, \dagger}$ and Gopal Achari 4}

1 Department of Chemistry, University of Calgary, 2500 University Dr. NW, Calgary, AB T2N 1N4, Canada

2 Department of Chemistry University of Calgary, 2500 University Dr. NW, Calgary, AB T2N 1N4, Canada; E-Mail: izadifam@ucalgary.ca

3 Department of Water Pollution Research, National Research Centre, Cairo 12311, Egypt; E-Mail: emadk80@gmail.com

4 Department of Civil Engineering, University of Calgary, 2500 University Dr. NW, Calgary, AB T2N 1N4, Canada; E-Mail; gachari@ucalgary.ca

$\dagger$ These authors contributed equally to this work.

* Author to whom correspondence should be addressed; E-Mail: chlangfo@ucalgary.ca; Tel.: +1-403-220-3228.

External Editor: Pierre Pichat

Received: 21 August 2014; in revised form: 31 October 2014 / Accepted: 5 November 2014 / Published: 26 November 2014

\begin{abstract}
Adsorb and shuttle (A/S) and interfacial charge transfer are the two major strategies for overcoming recombination in photocatalysis in this era of nanoparticle composites. Their relationships are considered here. A review of key literature is accompanied by a presentation of three new experiments within the overall aim of assessing the relation of these strategies. The cases presented include: $\mathrm{A} / \mathrm{S}$ by a high silica zeolite $/ \mathrm{TiO}_{2}$ composite, charge transfer (CT) between phases in a $\mathrm{TiO}_{2} / \mathrm{WO}_{3}$ composite and both $\mathrm{A} / \mathrm{S}$ and $\mathrm{CT}$ by composites of $\mathrm{TiO}_{2}$ with powered activated carbon (AC) and single-walled carbon nanotubes (SWCNT). The opportunities presented by the two strategies for moving toward photocatalysts that could support applications for the removal of contaminants from
\end{abstract}


drinking water or that lead to a practical adsorbent for organics that could be regenerated photocatalytically link this discussion to ongoing research here.

Keywords: $\mathrm{TiO}_{2}$; photocatalysis; adsorb and shuttle; charge transfer; electron storage; carbon; zeolite; $\mathrm{WO}_{3}$

\section{Introduction}

At present, the vast majority of the commercial application of photocatalysis depends on passive processes that may accomplish their photochemical goals slowly. This is a consequence of the small quantum yields typically reported and the limited UV energy available from low free or the low cost sources, either sunlight or fluorescent lamps installed for lighting purposes. Earlier in development of photocatalysis, major effort was expended on modification of the structure of $\mathrm{TiO}_{2}$ to overcome one or both of the limitations. So far, radical improvement has eluded researchers. In recent years, improvement in manipulating the chemistry of the nanoscale has fueled a fresh campaign to achieve improvement by creating hybrids of the photocatalyst with other phases, such that the field of applications might expand. Two key strategies can be found in the literature. One is the combination of a phase with $\mathrm{TiO}_{2}$ that can act as an acceptor for either the conduction band electron or the valence band hole to substantially inhibit recombination. The other is the "adsorb and shuttle" strategy that combines a phase that more extensively adsorbs the substrate and delivers it by surface diffusion to an adjacent $\mathrm{TiO}_{2}$ site. Using an adsorbent, which could be photocatalytically generated, is advantageous for drinking water and waste water photocatalytic treatment systems. These two strategies emerged before the nanoparticle outburst, and some fundamental aspects from earlier studies will be discussed below along with more recent key references. Some new results will be reported. The transfer of carriers between phases with electron transfer from $\mathrm{TiO}_{2}$ to $\mathrm{WO}_{3}$ is an area related to the water program. The two oxides have little difference in adsorption, making this nearly a "pure" charge transfer case. Results for a pure adsorb and shuttle case will come from a study of zeolite ZSM-5 on $\mathrm{TiO}_{2}$, a candidate in the effort to produce adsorbents that are photocatalytically regenerated. Finally, some results for the mixed case of carbon and $\mathrm{TiO}_{2}$ will be discussed.

\subsection{Adsorb and Shuttle (A/S)}

The key issues with $\mathrm{A} / \mathrm{S}$ were elucidated in a series of studies from Yoneyama's laboratories in the late 1990s. The approach involved loading a large excess of $\mathrm{TiO}_{2}$ onto particles of well-known adsorbents. In the case of the substrate, 3,5-dichloro- $N$-(3-methyl-1-butyn-3-yl)benzamide (propyzamide), photodegradation was studied using photocatalyst coated onto clays, zeolites and activated carbon [1]. The catalysts were all $70 \mathrm{wt} \% \mathrm{TiO}_{2}$. Adsorption isotherms fitted the Langmuir model. The Langmuir maximum adsorption capacity parameter was critical, but so was the specific initial extent of adsorption after dark equilibration, a measure of adsorption "strength". Apparently, the decomposition rate (measured as the sum of solution and adsorbed loss) of propyzamide was large in the order of naked $\mathrm{TiO}_{2}>70$ wt $\% \mathrm{TiO}_{2} /$ mordenite $>70$ wt $\% \mathrm{TiO}_{2} / \mathrm{SiO}_{2}>70$ wt $\% \mathrm{TiO}_{2} / \mathrm{AC}$ 
(activated carbon), the order being opposite of the order of the Langmuir adsorption constant (strength), except for $\mathrm{SiO}_{2}$. This appears to suggest that adsorb and shuttle was not useful. However, the rate of $\mathrm{CO}_{2}$ production (mineralization, the goal of most work) was in the order: $70 \mathrm{wt} \% \mathrm{TiO}_{2} / \mathrm{AC}$ $>70$ wt $\% \mathrm{TiO}_{2} / \mathrm{SiO}_{2}>70 \mathrm{wt} \% \mathrm{TiO}_{2} /$ mordenite $>$ naked $\mathrm{TiO}_{2}$. This is exactly the order of the initial adsorbate loading of the photocatalysts at initiation of irradiation. The important following point is that tracking of intermediates showed that most were in solution in the case of bare $\mathrm{TiO}_{2}$, but the overwhelming majority of intermediates was adsorbed in the case of $\mathrm{TiO}_{2} / \mathrm{AC}$. Thus, adsorb and shuttle can be a powerful tool for retaining intermediates and the completion of mineralization.

The key point of adsorb and shuttle, $\mathrm{A} / \mathrm{S}$, is that the concentration of the substrate close to the $\mathrm{TiO}_{2}$ surface should greatly increase the probability of meeting between the substrate and a photoactivated site. An elementary illustration of this is the increase of a quantum yield when a favourable substrate concentration is raised, as is the case of an increase of quantum yield from 0.001 to 0.15 as the propanol concentration is raised from 0.001 $\mathrm{M}$ to $0.05 \mathrm{M}$ [2]. Moreover, it is known that interfacial redox can compete well with recombination. For example, Colombo and Bowman [3] provide evidence that electron transfer can compete with recombination on a femtosecond time scale for particles encountering. Still, for the adsorbed substrate to reach the active site, it must migrate by surface diffusion. Consequently, surface diffusion must not be slow. Using propionaldehyde as a substrate, the relative surface diffusion was estimated on films containing $\mathrm{TiO}_{2}$ by following the consumption of all of the substrate on a film illuminated over a part of the area. Takeda et al. [4] found relative surface diffusion to be in the order $\mathrm{TiO}_{2} /$ mordenite $>\mathrm{TiO}_{2} /$ silica $>\mathrm{TiO}_{2} /$ alumina $>\mathrm{TiO}_{2} / \mathrm{AC}>$ $\mathrm{TiO}_{2} /$ zeolite A. An interesting related example of the problem of surface diffusion arose in an effort to produce a practical adsorbent based on a ZSM-5 hydrophobic zeolite absorber decorated with $\mathrm{TiO}_{2}$ to allow photocatalytic regeneration, a project that reached the pilot scale. Vaisman et al. [5] reported that as the adsorption capacity increased, the photocatalytic kinetics decreased proportionately.

In summary, effective adsorb and shuttle, A/S, requires adsorbents with a delicate balance of adequate adsorption capacity, sufficient absorption strength and facile surface mobility. As the systems described above suggest, the best case seems to be a large excess of $\mathrm{TiO}_{2}$ over the adsorbent.

\subsection{Interphase Charge Transfer}

The classic example of the reduction of the recombination rate is the deposition of small quantities of $\mathrm{Pt}$ on the $\mathrm{TiO}_{2}$ surface to capture electrons in the Pt phase. The literature is extensive. There are also a number of semiconductor oxides that could inhibit recombination in $\mathrm{TiO}_{2}$ if the matching of band gaps permits the transfer of an electron from the $\mathrm{TiO}_{2}$ conduction band to a lower band edge or permits the hole in the $\mathrm{TiO}_{2}$ conduction band to migrate to a higher energy conduction band edge. The examples are $\mathrm{WO}_{3}$, which can play the role of electron acceptor and $\mathrm{Ni}(\mathrm{OH})_{2}$, which can function as a hole acceptor. If the separation is to be long lived and build up in the acceptor phase, there must be electrochemical compensation. For example, if $\mathrm{WO}_{3}$ accepts electrons, we look to $\mathrm{W}(\mathrm{V})$ chemical traps requiring cationic compensation. Tatsuma et al. [6] demonstrated that the presence of ionic conduction through water could support long-lived energy storage by supplying $\mathrm{H}^{+}$as the cation (note that the $\mathrm{TiO}_{2}$ hole reacting with water produces a compensating $\mathrm{H}^{+}$). Oxygen discharge of the "stored" electrons in $\mathrm{WO}_{3}$ is slow, so energy storage providing reactivity in the dark is feasible. Thus, increased 
hole reactions from reduced recombination can be coupled to energy storage. Subsequently, Tatsuma et al. [7] demonstrated the bactericidal effect of the stored energy.

\subsection{Carbon}

Carbon has been mentioned above (along with a zeolite, silica or clay) as an adsorbent. It is, of course, the most widely used adsorbent for organics. However, there is also significant direct evidence of excited state electron transfer from $\mathrm{TiO}_{2}$ to carbon. A striking example is the puzzle presented by Kedem et al. [8], who reported enhanced stability in polymer nanofibres containing $\mathrm{TiO}_{2}$ and carbon nanotubes (CNTs). The CNTs reduced the rate of photocatalytic degradation of the (polyacrylonitrile) matrix. However, this did not interfere with photocatalytic reactions with several organic substrates and even enhanced the degradation of rhodamine $6 \mathrm{G}$ dye. This set of conflicting results can be understood as the CNTs functioning to transport charge carriers from the $\mathrm{TiO}_{2}$ to $\mathrm{CNT}$ sites, which may induce a variety of effects (e.g., superoxide formation) depending on the degradation mechanism and reaction loci.

In combinations of carbon with photocatalysts, we must ask: what is the relative role of charge transfer $v s$. adsorb and shuttle?

The $6 \mathrm{G}$ dye measurements, made on aliquots of solution not accounting for the dye adsorbed on the CNTs, raises a final basic point. Xu and Langford [9] made an important observation about strongly adsorbed substrates using the dye XB3. For all the reactions induced by UV or visible light, the apparent initial rate of $\mathrm{X} 3 \mathrm{~B}$ loss in the aqueous phase increased with the initial equilibrated concentration of $\mathrm{X} 3 \mathrm{~B}$. However, when the rate was determined by the decreased concentration both in the aqueous phase and on the catalyst surface, increase of real initial rate with the initial equilibrated concentration was observed only in the visible-light-induced reaction. That is, only when the reaction was initiated by dye sensitization that initiates dye oxidation directly upon excitation. It is important to measure total degradation, solution and surface, as done in the work in Yoneyama's group cited above.

\section{Results and Discussion}

\section{1. $\mathrm{TiO}_{2} / \mathrm{ZSM}-5$ Adsorb and Shuttle}

The chosen adsorbent is the high silica zeolite ZSM-5 in a configuration similar to the system of Vaisman et al. [5] designed as an adsorbent for photocatalytic regeneration. ZSM-5, with a highly hydrophobic surface, presents an adsorption profile resembling activated carbon, but weaker for some highly hydrophobic molecules and stronger for more polar organics. It is used here in composite with Degussa $\mathrm{P} 25 \mathrm{TiO}_{2}$ (PZS). The percentages of three different model substrates adsorbed on the surface of PZS and P25 after 30 min of stirring in the dark are shown in Table 1. It can be seen that there is an unequivocal increase in the amount of the 2,4,6-trichlorophenol (2,4,6-TCP) substrate adsorbed on the surface of PZS with a drastic increase observed in the case of sulfamethoxazole (SMX), while for atrazine, the adsorption was the least. The overall order of increase in percent adsorption is $\mathrm{SMX}>2,4,6-\mathrm{TCP}>$ atrazine. 
Table 1. Adsorption percentage of the different model compounds at initial concentrations of $50.0 \mathrm{mg} / \mathrm{L}$ on the surface of PZS and P25 after the dark period. SMX, sulfamethoxazole; 2,4,6-TCP, 2,4,6-trichlorophenol.

\begin{tabular}{ccc}
\hline \multirow{2}{*}{ Compound } & \multicolumn{2}{c}{ Photocatalyst } \\
\cline { 2 - 3 } & Degussa P25\% & PZS\% \\
\hline SMX & 2.60 & 18.00 \\
$2,4,6-\mathrm{TCP}$ & 29.20 & 41.90 \\
Atrazine & 2.40 & 5.64 \\
\hline
\end{tabular}

Figure 1 compares the photocatalytic performance of the PZS to that of commercial Degussa P25 as a reference. The first point corresponds to the normalized concentration after the dark adsorption period. Pseudo first-order rate constants $(\mathrm{k})$ along with correlation coefficients $\left(\mathrm{R}^{2}\right)$ are listed in Table 2 (because of the rapid reaction, it was not a certain that the atrazine data do fit first order kinetics).

Figure 1. Photocatalytic degradation of the substrates with a UVA LED photoreactor. Solid lines, PZS (P25:ZSM-5:silica gel = 0.3:0.5:0.5 g/L); dashed lines, Degussa P25 $(0.3 \mathrm{~g} / \mathrm{L})$.

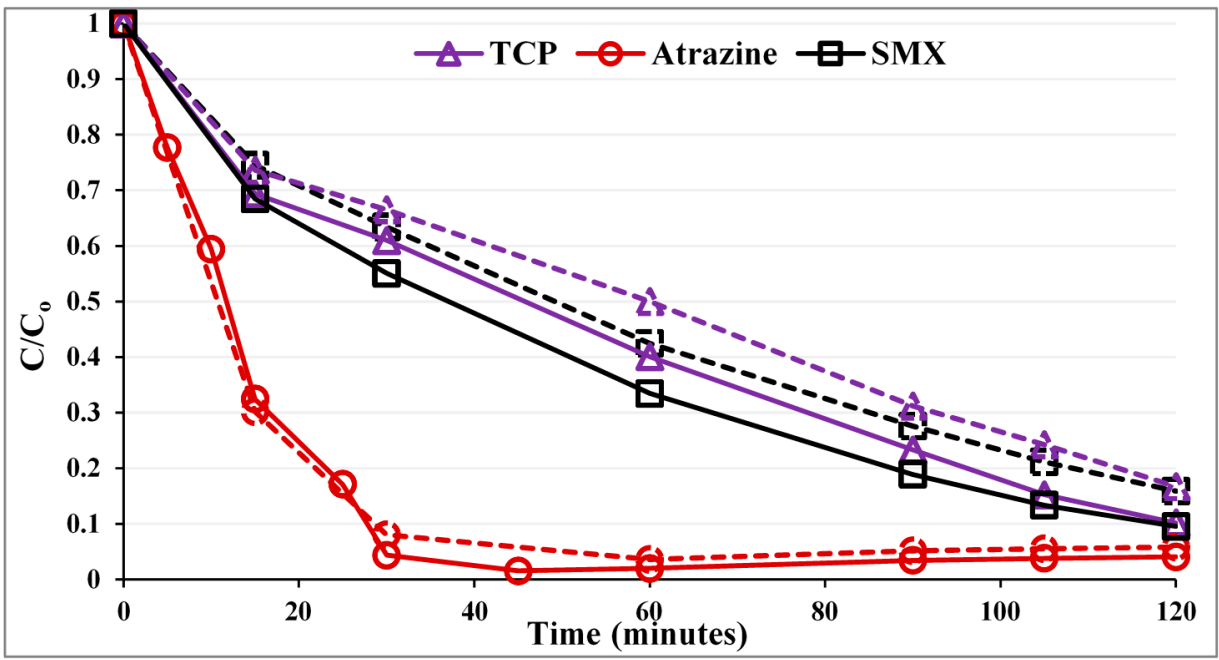

Table 2. Pseudo first order rate constants $\left(\mathrm{min}^{-1}\right)$ and $\mathrm{R}^{2}$ fit measure for the substrates.

\begin{tabular}{|c|c|c|c|c|}
\hline \multirow{2}{*}{$\begin{array}{c}\text { Compound } \\
\text { SMX }\end{array}$} & \multicolumn{2}{|c|}{ Degussa P25 min $^{-1}$} & \multicolumn{2}{|c|}{ PZS min $^{-1}$} \\
\hline & $\mathrm{k}=0.0147$ & $\mathrm{R}^{2}=0.996$ & $\mathrm{k}=0.0189$ & $\mathrm{R}^{2}=0.9965$ \\
\hline 2,4,6-ТCP & $\mathrm{k}=0.0137$ & $\mathrm{R}^{2}=0.977$ & $\mathrm{k}=0.0179$ & $\mathrm{R}^{2}=0.982$ \\
\hline Atrazine & $\mathrm{k}=0.055$ & $\mathrm{R}^{2}=0.923$ & $\mathrm{k}=0.0976$ & $\mathrm{R}^{2}=0.966$ \\
\hline
\end{tabular}

As can be seen in Figure 1, for SMX and 2,4,6-TCP, the PZS shows noticeably higher photocatalytic activity than the Degussa P25. The enhancement in efficiency is not in proportion, as the adsorption strength of these compounds on the zeolite surface is different. While for atrazine, the photocatalytic activity was within the error, the same for both Degussa P25 and PZS. The order of photocatalytic activity improvement is $\mathrm{SMX} \sim 2,4,6-\mathrm{TCP}>$ atrazine, which is consistent with the order of improved adsorption. This suggests that adsorb and shuttle may have been effective. 
Substrates were extracted to track the extent of the retention of the initial substrate on the adsorbent surface during reaction. The amounts are reported in units of the solution concentration equivalent. Figure 2 shows data for 60 and $120 \mathrm{~min}$.

Figure 2. Residue results of the substrates on the surface of PZS and Degussa P25 after one and two hour irradiation. The left bar shows 1-h data and the (clearly visible only for SMX) right bar 2-h data.

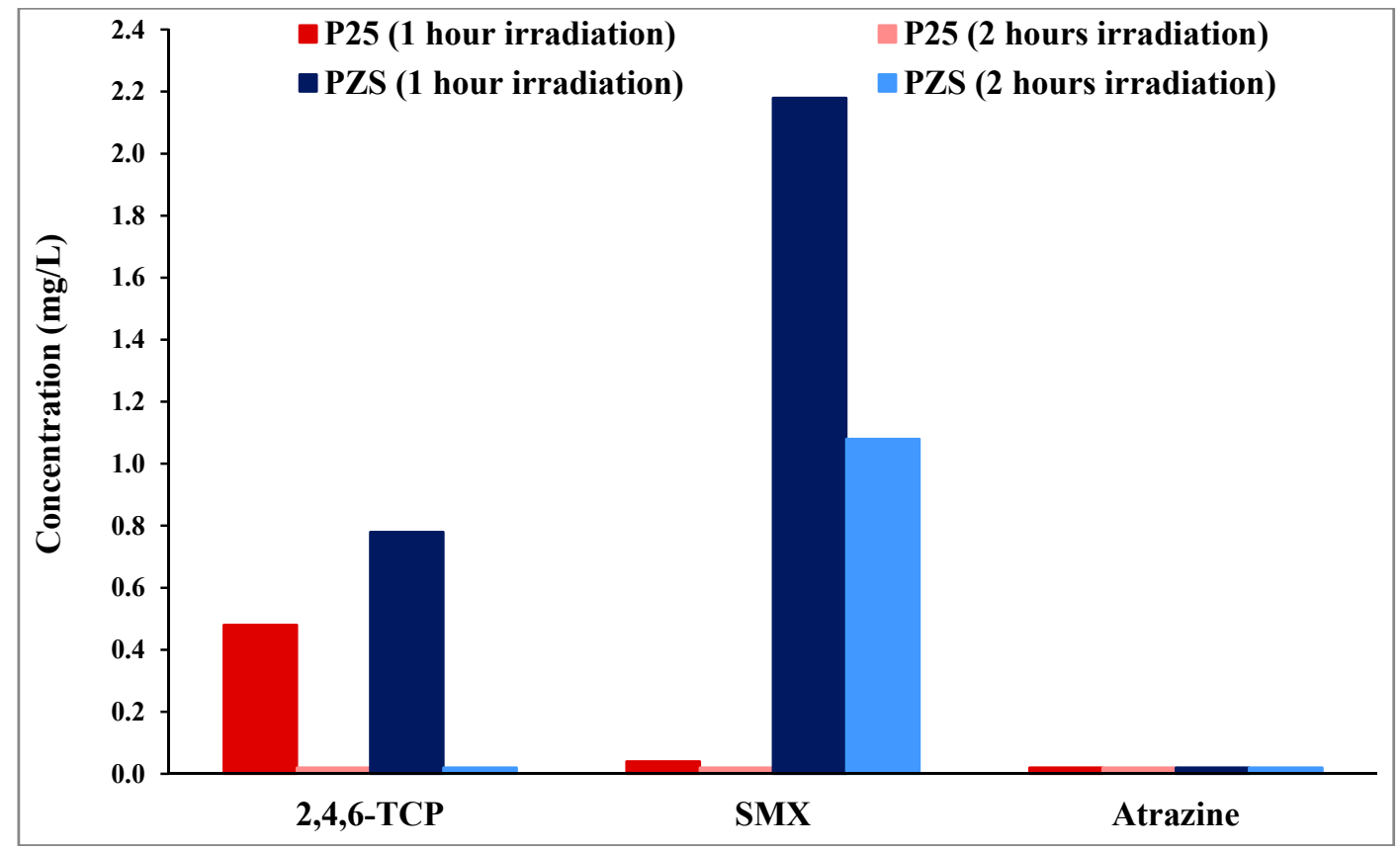

2,4,6-TCP residue on the surface of both photocatalysts after $1 \mathrm{~h}$ of irradiation was small (less than $1 \mathrm{mg} / \mathrm{L}$ solution equivalent compared to an initial total of $50 \mathrm{mg} / \mathrm{L}$ ). After $2 \mathrm{~h}$ of irradiation, no 2,4,6-TCP residues were detected on the surface of either photocatalyst. Furthermore, it can be seen from Figure 2 that, when the initial extent of dark adsorption is small, no residues were detected on the surface of either photocatalyst, as seen for atrazine on both photocatalysts and even for SMX on P25. The residue of SMX on the surface of PZS after $1 \mathrm{~h}$ of irradiation was $2.2 \mathrm{mg} / \mathrm{L}$, which reduced to $1 \mathrm{mg} / \mathrm{L}$ after $2 \mathrm{~h}$ of irradiation. The comparison of the initial extent of dark adsorption results (Table 1) with these results suggests that 2,4,6-TCP surface diffusion [4] is faster than SMX.

The key advantage of $\mathrm{A} / \mathrm{S}$ is the promotion of mineralization [1]. The percentage of TOC removal of the substrates using PZS and Degussa P25 after $1 \mathrm{~h}$ of irradiation is shown in Figure 3. Using PZS improves the mineralization of SMX and shows that $2,4,6$-TCP is $\sim 45 \%$ mineralized after $\sim 50 \%$ loss in the substrate. No mineralization of atrazine is seen, in agreement with McMurray et al. [10].

The results are a reminder that atrazine is one of the rare compounds not mineralized on $\mathrm{TiO}_{2}$. The reaction stops at cyanuric acid [10]. 
Figure 3. Percentage TOC removal after $1 \mathrm{~h}$ of irradiation.

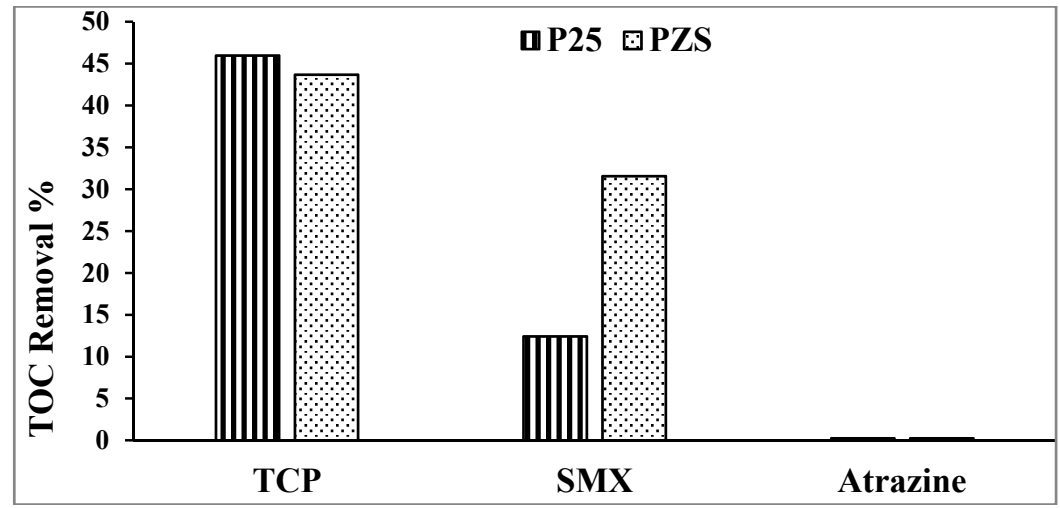

\subsection{Interphase Charge Transfer: $\mathrm{TiO}_{2} / \mathrm{WO}_{3}$}

One of the most striking demonstrations of the reduction of recombination rates arises from the persistence of reactivity after irradiation is terminated [11]. In this experiment, 4-chlorophenol (4-CP) was chosen as a substrate to avoid any A/S contribution. Figure 4 shows the percent degradation of 4-CP after one hour of irradiation in a slurry of $\mathrm{TiO}_{2} / \mathrm{WO}_{3}$ in a 33-ppm solution of the 4-CP using the 365-nm LED reactor to allow precise pulsing. The duty cycle is varied. The figure shows the striking case of the efficiency increase in degradation reactions of 4-chlorophenol. A 1:1 duty cycle at a constant total dose with a pulse time of 10 minutes $\left(10^{4} \mathrm{~ms}\right)$ increases the efficiency of energy utilization by almost a factor of two. Titration of available electrons after termination of illumination by $\mathrm{Fe}(\mathrm{III})$ reduction is shown in Figure 5.

Figure 4. Pulsed vs. continuous irradiation in a 365-nm LED reactor degrading 4-chlorophenol (4-CP). Charge is $0.05 \mathrm{~g} \mathrm{WO}_{3} / \mathrm{TiO}_{2}$ and $5 \mathrm{~mL}$ of $33 \mathrm{mg} / \mathrm{L} 4-\mathrm{CP}$ receiving $(4.3 \pm 0.2) \times 10^{16}$ photons $/ \mathrm{s}$. Total irradiation: $60 \mathrm{~min}$ in each case, duty cycle (ratio minute light:minute dark) varied.

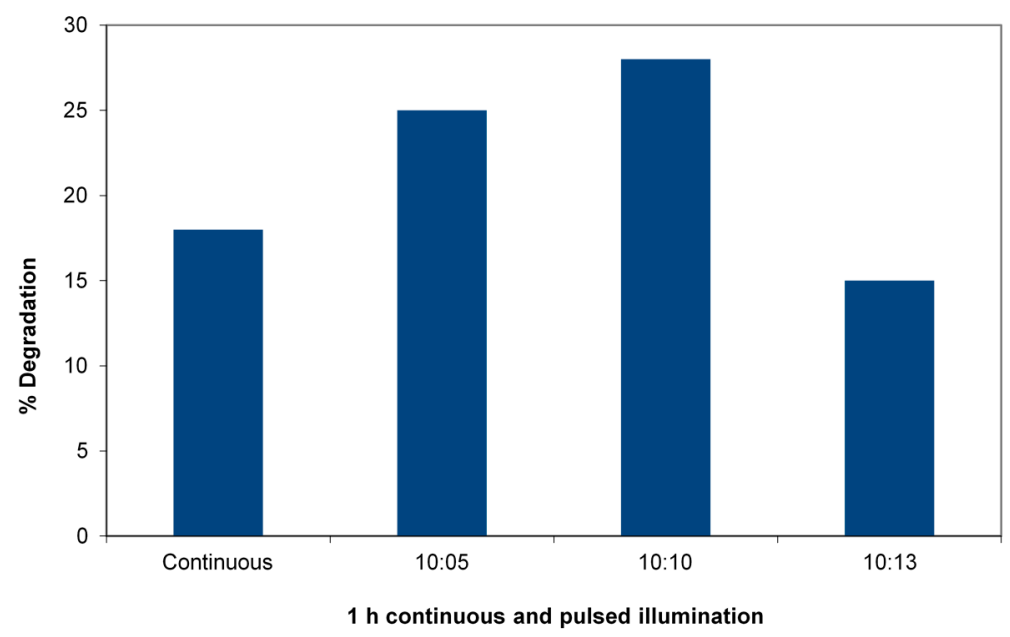

The extent of electron storage during the photodegradation of 4-CP was monitored by rapid titration with $\mathrm{Fe}$ (III) of a sample of the solution after successive times of illumination. Figure 5 shows the levels during the degradation of the $33 \mathrm{mg} / \mathrm{L}$ sample, as described above. 
Figure 5. Stored electron levels during the photocatalytic degradation of 4-CP measured by $\mathrm{Fe}(\mathrm{III})$ titration with $\mathrm{Fe}(\mathrm{II})$ detection by phenanthroline complexation.

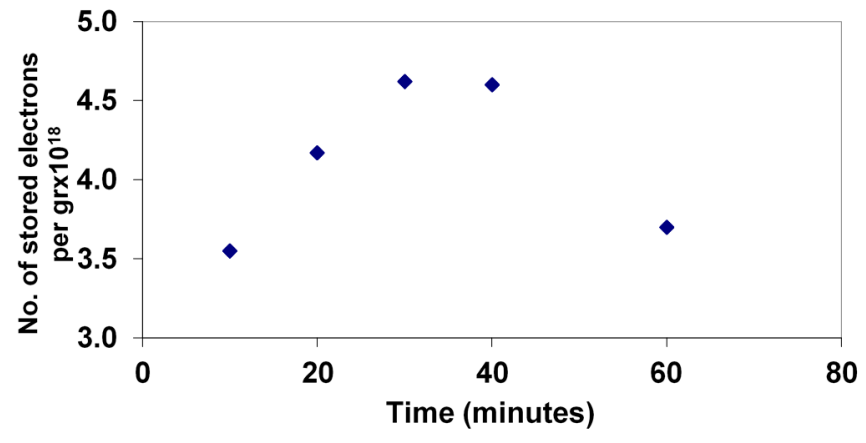

It has been reported [7] that charge storage with $\mathrm{WO}_{3}$ allows inhibition of $E$. coli that are exposed in the dark to $\mathrm{TiO}_{2} / \mathrm{WO}_{3}$. This is confirmed by data in Table 3, where illumination was UVA (365 nm), and the sample was outflow water from a secondary wastewater treatment plant. This water contains a mix of other organic molecules that can compete for reaction with excited $\mathrm{TiO}_{2} / \mathrm{WO}_{3}$. A $50-\mathrm{mL}$ waste water sample with 10-ppm fulvic acid (FA) solution (as a supplemental hole scavenger) $+0.33 \mathrm{~g}$ $\mathrm{WO}_{3}-\mathrm{TiO}_{2}$ was used. In a first experiment, $50 \mathrm{~mL}$ of contaminated water was added to the $\mathrm{TiO}_{2}$ slurry, and the mixture was incubated for $5 \mathrm{~h}$. In the subsequent experiment, after $30 \mathrm{~min}$ in the dark, the slurry was irradiated for $2 \mathrm{~h}$ in the 365-nm LED reactor. Post irradiation, the 50-mL contaminated water sample was added and incubated for $5 \mathrm{~h}$. The samples were measured for coliforms by the Colilert tray method, widely used for water monitoring. Note that the initial sample counts are not reproducible due to the biological activity in the stock.

Table 3. Coliform counts after exposure to $\mathrm{TiO}_{2} / \mathrm{WO}_{3}$ without and with pre-charging for $2 \mathrm{~h}$. (MPN = most probable number of colonies).

\begin{tabular}{cccc}
\hline Sample & Total Coliform (MPN) & $\boldsymbol{E}$ coli $(\mathbf{M P N})$ & Decrease in $\boldsymbol{E}$. coli \\
\hline Stock solution & $1,921.2$ & 246.8 & \\
$\mathrm{WO}_{3} / \mathrm{TiO}_{2}$ (dark blank) & 872.0 & 161.0 & $35 \%$ \\
$\mathrm{Stock}$ solution & $1,732.9$ & 488.4 & \\
$\mathrm{WO}_{3} / \mathrm{TiO}_{2}$ charged & 108.4 & 26.6 & $95 \%$ \\
\hline
\end{tabular}

\subsection{Carbon}

Carbon is a good adsorbent and can act as an electron acceptor [12]. Consequently, both mechanisms may arise. An interesting potential application is the removal of emerging contaminants from water. For this reason, composites were made using the well-established $\mathrm{TiO}_{2}$, Degussa $\mathrm{P} 25$ reference point. Figure 6 shows the adsorption isotherms for SMX on P25 loaded with 5\% by weight of either AC or SWCNTs or $0.25 \%$ by weight of SWCNTs. These values are chosen, because preliminary results show good rates for photocatalysts with $0.25 \%$ SWCNTs and $5 \%$ activated carbon (AC).

The comparative amounts adsorbed as a function of the loading of carbon on $\mathrm{TiO}_{2}$ is interesting and offers a possible explanation for the preliminary observation that 5.0\% AC and $0.25 \%$ SWCNTs were both favourable loadings for the study of the photocatalytic reaction. The amounts of SMX adsorbed are similar. 
Figure 6. Adsorption isotherms at $22{ }^{\circ} \mathrm{C}$ for SMX on activated carbon (AC) or single-walled carbon nanotubes (SWCNT). SWCNT: solid line, $5.0 \%$ by weight; dashed line, $0.25 \%$ by weight. $\mathrm{C}_{\mathrm{e}}=$ solution concentration; $\mathrm{q}_{\mathrm{e}}=$ adsorbed weight per unit mass $(\mathrm{mg} / \mathrm{g})$.

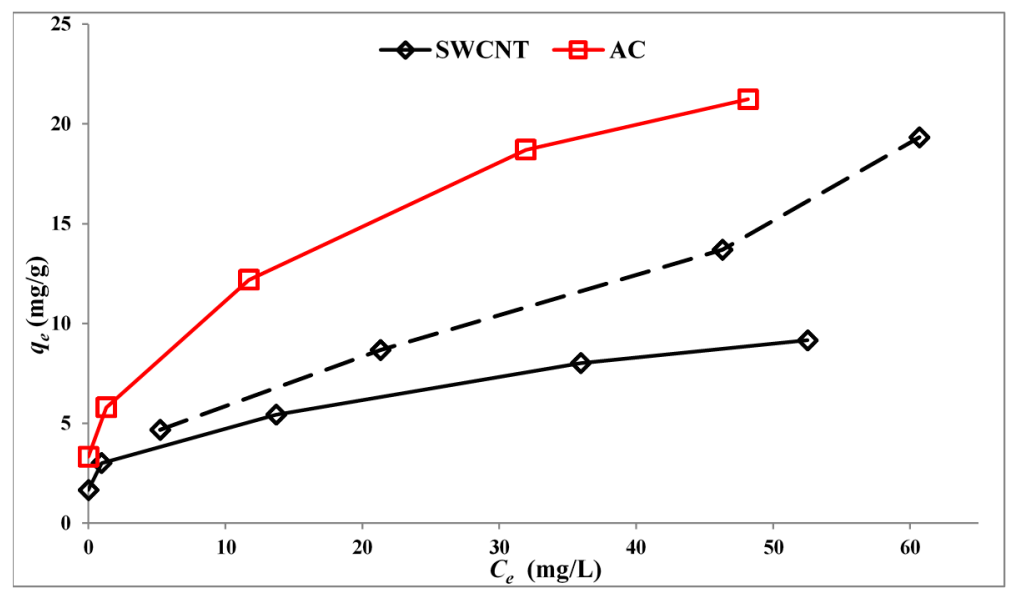

A series of representative results for SMX degradation on the three photocatalysts are collected below for a photocatalyst loading of $1.0 \mathrm{~g} / \mathrm{L}$ and initial solution SMX concentrations of $2.4 \times 10^{-4} \mathrm{M}$. After the dark adsorption equilibration period, solution concentrations were $1.1 \times 10^{-4} \mathrm{M}$ for P25/AC, $2.3 \times 10^{-4} \mathrm{M}$ for P25 and $1.4 \times 10^{-4} \mathrm{M}$ for P25/SWCNT. Table 4 collects the rate constants. The rate constants for the total loss of substrate are compared in the table to apparent "rate constants" calculated from solution concentrations alone. Where adsorption is small (P25), the solution value is in agreement. However, differences are quite significant when carbon is added. The data shown here are a reminder that many rate constants in the literature have been reported on solution data where adsorption may have been significant. This can be quite misleading. It is especially true for studies involving dye molecules [9]. Figure 7 shows the kinetics of total SMX loss with P25, P25/AC and P25/SWCNT as photocatalysts plotted as first order reactions. Powdered activated carbon appears to act as an inhibitor in these circumstances. SWCNTs may be marginally accelerating. This is consistent with reports that surface diffusion is faster on SWCNTs than powdered activated carbon [8].

Table 4. First order rate constants for the total loss of $\operatorname{SMX}\left(4.2 \times 10^{-4} \mathrm{M}\right)$ with three photocatalysts.

\begin{tabular}{cccc}
\hline Photocatalyst & Rate Constant $\left(\mathbf{m i n}^{-\mathbf{1}}\right)$ & $\mathbf{R}^{\mathbf{2}}$ Fitting Parameter & $\begin{array}{c}\text { Apparent Solution } \\
\text { "Rate Const." }\left(\mathbf{m i n}^{\mathbf{- 1}}\right)\end{array}$ \\
\hline P25/AC & 0.0103 & 0.988 & 0.0154 \\
P25 & 0.0165 & 0.980 & 0.0166 \\
P25/SWCNT & 0.0173 & 0.990 & 0.0227 \\
\hline
\end{tabular}

In an effort to detect possible electron storage from charge transfer in $\mathrm{TiO}_{2} / \mathrm{SWCNTs}$ composites, reactions were carried out in the pulse irradiation mode with pulse cycle times down to $100 \mathrm{~ms}$, with duty cycles of $50 \%, 30 \%$ and $10 \%$. (with the relaxation time of $\mathrm{TiO}_{2}$ alone near $70 \mathrm{~ms}$. [13]l a shorter pulse time would not distinguish carbon effects). In no case was a significant difference between pulse irradiation and continuous irradiation observed for a constant energy dose. This could suggest that the SWCNTs function only in the A/S mode, but the alternative explanation, given the direct evidence for 
electron transfer, is that carbon mediates rapid electron transfer to $\mathrm{O}_{2}$. There is evidence that nanocarbon can function as an efficient conductor, delivering the electrons [8] to an acceptor. Yao et al. [12] reported results for a physical mixture of carbon nanotubes with $\mathrm{TiO}_{2}$ nanotubes. The solution conversion rates were superior to $\mathrm{TiO}_{2}$ alone, but the physical mixture rate was only about half of the composite rate. The positive effect in a physical mixture was taken to be evidence of electron transfer. It does seem unlikely that the time of an encounter would allow efficient shuttle action, unless encounters are "sticky". Yao et al. used a dispersant to minimize this. An experiment with a physical mixture of P25 with SWCNTs (ratio as above) started from $95 \mathrm{mg} / \mathrm{L}$ SMX, which led to a surface concentration equivalent to $24 \mathrm{mg} / \mathrm{L}$ after dark adsorption (clearly carbon loading). Four hours of irradiation reduced the solution concentration and the surface residual to values comparable to those for the composite, tending to support a role for electron transfer.

Figure 7. Kinetics of the total loss of SMX on irradiation of slurries in a $365-\mathrm{nm}$ batch reactor.

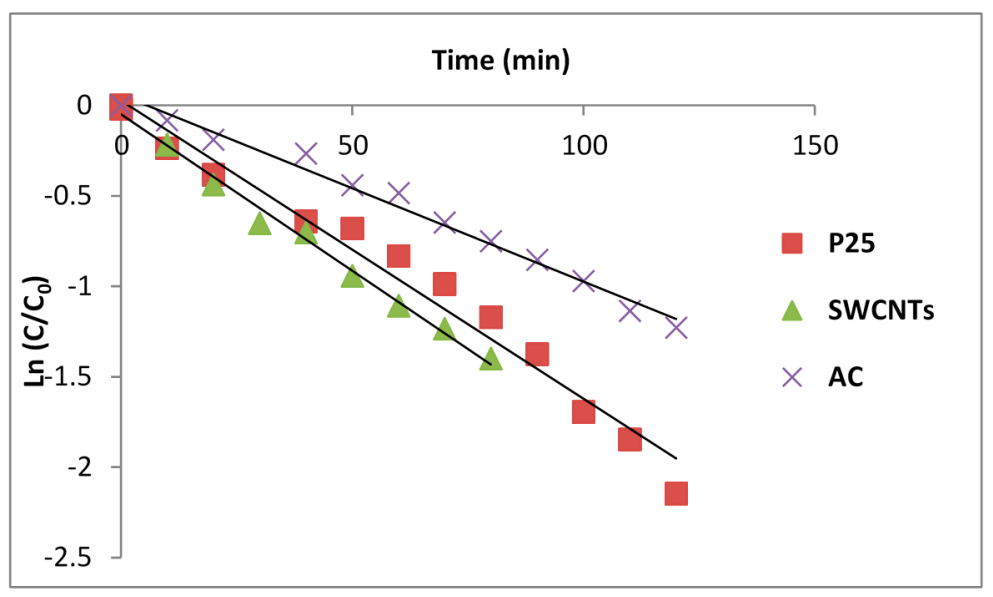

\subsection{Discussion}

\subsubsection{Adsorb and Shuttle (A/S)}

The new photocatalyst is assembled in a silica matrix. This resembles the systems described in Vaisman et al. [5] that were used to construct an adsorbent to be regenerated photocatalytically. Since good results are achieved with an excess of adsorbent over $\mathrm{TiO}_{2}$, the adsorbent that is regenerated may be a good A/S target. The kinetic behaviour for the decrease of three substrates is reported in Figure 1. The TOC data in Figure 3 underlines the key advantage of A/S. Intermediates are retained on the photocatalyst assembly, and mineralization is favoured as observed by Torimoto et al. (1996). In the regeneration application, mineralization is important and may lead to the choice of a poorer catalyst for the loss of the initial target compound. The key challenge to the use of $\mathrm{A} / \mathrm{S}$ is that adsorb and shuttle systems are highly dependent on the substrate.

\subsubsection{Interphase Charge Transfer}

A system to unambiguously demonstrate the transfer of carriers that inhibit recombination needs to minimize the potential for $\mathrm{A} / \mathrm{S}$. $\mathrm{WO}_{3}$ may be a better adsorbent for some organic substrates than $\mathrm{TiO}_{2}$, 
but the difference is not as great as with ZSM-5 or carbons. To further minimize A/S, a reaction with a weakly adsorbed substrate can be chosen. In this case, 4-chlorophenol is the chosen substrate. The pulse experiment is the most striking demonstration of the reduction of recombination, since it requires that carriers may remain to react after the light goes off. $\mathrm{TiO}_{2}$ itself will have a short relaxation time for a reaction to occur after illumination stops, determined by the longest kinetic components of the recombination in $\mathrm{TiO}_{2}$. This is on the order of $\sim 70 \mathrm{~ms}$ [13]. With LED light sources, it could be feasible to examine a pulsing time below this limit, but the present system needed only minute-scale on-off sequences. A potentially practical application of a reduced recombination storing charge is shown, an increase in the light energy efficiency by optimizing the pulse widths and duty cycle in pulsed illumination. Of course there is a trade off in longer the overall residence time required to receive the dose.

Dark E. coli inhibition suggests that a system like $\mathrm{TiO}_{2} / \mathrm{WO}_{3}$ might overcome the limitation on a recycling design of a solar reactor for water disinfection plants, since the potential for organism regrowth in the dark phase of the recycle operation has been considered a barrier to the use of recycling.

\subsubsection{Carbon}

Carbon presents the problem of a co-catalyst that may play either of the two roles or both. For example, Torimoto et al. [1] included activated carbon as an effective adduct to $\mathrm{TiO}_{2}$ among a list of adsorbents. In contrast, Yao et al. [12] report an elegant series of experiments with composites of carbon nanotubes and nano- $\mathrm{TiO}_{2}$ that are interpreted entirely in terms of electron transfer to carbon. The transfer is verified by photoluminescence quenching. Twenty to one ratios of $\mathrm{TiO}_{2}$ to $\mathrm{SWCNTs}$ gave their largest rate enhancement. The argument for electron transfer ( $v s . \mathrm{A} / \mathrm{S})$ is further strengthened by observations on physical mixtures of $\mathrm{C}$ with $\mathrm{TiO}_{2}$. However, only solution concentrations of the phenol substrate were reported, and surprisingly, measurements of remaining TOC after $4 \mathrm{~h}$ showed that P25 alone achieved the greatest carbon reduction $(\sim 80 \%)$. The most effective catalyst of phenol loss ( $>80 \%$ degradation in one hour) reduced TOC by only about ten percent in $4 \mathrm{~h}$. The long lifetimes of intermediates suggests that $\mathrm{A} / \mathrm{S}$ may have played a role. Data for surface residuals for [11] experiments would help to clarify.

If carbon nanotubes are good electron acceptors, why are efforts to measure energy storage more limited than $\mathrm{TiO}_{2} / \mathrm{WO}_{3}$ ? It was noted that $\mathrm{W}(\mathrm{V})$ can be stabilized by the capture of a cation and that the hole site reacts with water to provide a compensating $\mathrm{H}^{+}$. In contrast, carbon is perhaps the better conductor to pass the electron on to, e.g., $\mathrm{O}_{2}$. Good energy storage systems need a good way to stabilize the separated charges.

Here, experiments with two forms of carbon modeled after the literature, the common adsorbent activated carbon [1] and single-walled carbon nanotubes [12], are reported. Carbon has been reported to affect the band gap and absorbance limit of $\mathrm{TiO}_{2}$. Irradiation with 365-nm LEDs assures comparison of the same energetic preparation of the excited state of $\mathrm{TiO}_{2}$, which helps to focus on $\mathrm{A} / \mathrm{S}$ versus charge transfer. The chosen substrate, SMX, is an agricultural antibiotic that is efficiently adsorbed by carbon, giving both pathways an opportunity. The results are mixed and suggest that both are involved. 
However, the pulse results imply that electron transfer must be accompanied by efficient transfer to oxygen. This then implicates the superoxide ion produced as a key player in the pathway.

\section{Materials and Methods}

\subsection{Materials}

$\mathrm{TiO}_{2}$ (Degussa P25) powder $\left(50 \mathrm{~m}^{2} / \mathrm{g} ; 15 \%-30 \%\right.$ rutile $+85 \%-70 \%$ anatase) was purchased from Degussa. Zeolite ZSM-5 $\left(400 \mathrm{~m}^{2} / \mathrm{g}\right.$; Si/Al = 280) was purchased from Zeolyst International and calcined at $500{ }^{\circ} \mathrm{C}$ for an hour. Silica gel with particle sizes of $0.2-0.5 \mathrm{~mm}$ was purchased from Acros Organic. Single-walled carbon nanotubes (SWCNTs) and powdered activated carbon (AC) were obtained from Sigma-Aldrich and used as obtained without further purification. Sulfamethoxazole (SMX), 2,4,6-trichlorophenol (2,4,6-TCP), atrazine and 4-chlorophenol (4-CP) were selected as model substrates for organic pollutants for this report. They were purchased from Sigma-Aldrich and used as received. High performance liquid chromatography (HPLC)-grade acetonitrile and HPLC-grade water were used as a mobile phase in HPLC. Methyl alcohol, ACS grade, was purchased from Sigma-Aldrich. All of the solutions were prepared using "deionized" water (DI) from a Milli-Q system and characterized by its resistivity (18.2 $\mathrm{M} \Omega$ ).

\subsubsection{Synthesis of ZSM-5 Containing Catalyst}

A three-component ( $\mathrm{TiO}_{2}, \mathrm{ZSM}-5$ and silica gel) composite photocatalyst was prepared as follows. First, ZSM-5 and $\mathrm{TiO}_{2}$ were separately dispersed in $20 \mathrm{~mL}$ of methanol and sonicated for $30 \mathrm{~min}$. Then, the ZSM-5 suspension was added to the $\mathrm{TiO}_{2}$ suspension during stirring, and the ZSM-5/TiO 2 suspension was stirred for $15 \mathrm{~min}$. This was followed by adding the silica gel powder during stirring, which continued for 15 more min. Finally, the methanol was evaporated while stirring; the composite catalyst was dried in an oven at $100{ }^{\circ} \mathrm{C}$. then calcined in a furnace at $500{ }^{\circ} \mathrm{C}$ for $3 \mathrm{~h}$. The composite catalyst components weights were maintained to obtain a ratio of $\mathrm{TiO}_{2}: \mathrm{ZSM}-5$ :silica gel $=0.3: 0.5: 0.5$ in the finished form of the catalyst. Above, PZS is used to refer to this ZSM-5-containing composite catalyst.

\subsubsection{Synthesis of $\mathrm{TiO}_{2} / \mathrm{WO}_{3}$ Composite}

$\mathrm{WO}_{3} / \mathrm{TiO}_{2}$ composite was prepared based on a sol-gel method [12] with titanium isopropoxide and phosphotungstic acid $\left(\mathrm{H}_{3} \mathrm{PW}_{12} \mathrm{O}_{40}\right)$ as precursors. Titanium isopropoxide $(3.0 \mathrm{~mL})$ and a specific amount of $\mathrm{H}_{3} \mathrm{PW}_{12} \mathrm{O}_{40}$ were dissolved in $20 \mathrm{~mL}$ of isopropyl alcohol and deionized water, respectively. The alcohol solution was then added dropwise to the aqueous solution. After aging for $2 \mathrm{~h}$, the white gel formed was dried at $100{ }^{\circ} \mathrm{C}$ and sintered at $500{ }^{\circ} \mathrm{C}$ for $5 \mathrm{~h}$. The crystalline structure of this photocatalyst is reported to be anatase with an average particle size of $9.5-10 \mathrm{~nm}$ and a molar ratio of 0.04 for $\mathrm{W} / \mathrm{Ti}[12]$.

\subsubsection{Synthesis of Carbon/ $\mathrm{TiO}_{2}$ Composites}

$\mathrm{TiO}_{2} / \mathrm{SWCNTs}$ and $\mathrm{TiO}_{2} / \mathrm{AC}$ composites with different mass ratios were prepared by a simple evaporation and drying process according to Yao et al. [12]. First, AC or SWCNTs were dispersed 
in $100 \mathrm{~mL}$ of water and sonicated for $10 \mathrm{~min}$. $\mathrm{TiO}_{2}$ powder was added to the suspension and sonicated for 20 more minutes. Then, the suspension containing $\mathrm{AC}$ or $\mathrm{CNTs}$ and $\mathrm{TiO}_{2}$ particles was heated to $80{ }^{\circ} \mathrm{C}$ while stirring with air flowing across the suspension's surface to accelerate the evaporation of water. After the water evaporated, the composite was dried overnight in an oven at $104{ }^{\circ} \mathrm{C}$. SWCNT composites were characterized by SEM and EDX. Carbon is found to be non-homogeneously distributed over the $\mathrm{TiO}_{2}$. EDX measurements show that SWCNTs penetrate into the space between individual crystallites in the commercial $\mathrm{TiO}_{2}$ aggregates.

\subsection{Adsorption Isotherms}

Adsorption studies were carried out in a batch mode as follows. Accurately weighed amounts of catalysts were added separately into glass vials containing an exact volume $(20.0 \mathrm{~mL})$ of different known initial concentrations of SMX. The glass vials were stirred in the dark for $45 \mathrm{~min}$; then, the samples were filtered with a $0.20-\mu \mathrm{m}$ syringe filter, and the residual concentration of SMX was measured. The amount of adsorbate uptake capacity at equilibrium, $q_{e}$, was calculated by mass balance as follows:

$$
q_{e}=\frac{\mathrm{V}\left(C_{i}-C_{e}\right)}{\mathrm{m}}
$$

where $q_{e}$ is the equilibrium amount of solute adsorbed per unit mass of adsorbent $(\mathrm{mg} / \mathrm{g})$ and $C_{i}$ and $C_{e}$ are the initial and the equilibrium concentrations of the solute $(\mathrm{mmol} / \mathrm{L})$ in solution, respectively. $\mathrm{V}$ is the volume of the solution, and $\mathrm{m}$ is the weight of the adsorbent $(\mathrm{g})$.

\subsection{Photocatalytic Procedures}

In all cases, the reactivity of the photocatalysts was measured as the disappearance of the substrate compounds (SMX, 2,4,6-TCP 4-Cl-phenol and atrazine). Accurately weighed amounts of different prepared photocatalyst composites were dispersed separately into a glass vial containing an exact volume $(20.0 \mathrm{~mL})$ of known initial concentration of the model substrates in a single component system. After 30 min of dark stirring, the suspension was irradiated. The reaction vessels were placed in a circular bench-scale 365-nm LED photoreactor, locally fabricated [14]. The inside diameter and depth of the reactor are 9 and $7 \mathrm{~cm}$, respectively, and it is equipped with 90 LED 3-mW output lamps (NSHU5518), which are evenly distributed in 15 rows. The light intensity in the vessel was $(4.3 \pm 0.2) \times 10^{16}$ photons/s. A sample was withdrawn at pre-determined time intervals, centrifuged, filtered using a $0.2-\mu \mathrm{m}$ syringe filter, and the residual concentration was measured by HPLC. Some surface concentrations were estimated from isotherms. In selected cases, compounds on the surface of composites and Degussa P25 were extracted with acetonitrile, centrifuged, filtered and the concentration measured by HPLC. Samples for total organic carbon (TOC) (irradiated for one to two hours) were centrifuged, passed through a $0.45-\mu \mathrm{m}$ syringe filter and analyzed using an Apollo 9000 combustion TOC analyzer equipped with an autosampler.

\subsection{Analytical Procedures}

HPLC: A "Varian pro star 210" HPLC equipped with a PFP 100A column (Phenomenex kinetix ${ }^{\mathrm{TM}}$ $2.6 \mu \mathrm{m}$, LC Column $100 \times 4.6 \mathrm{~mm}$ ) with $20-\mu \mathrm{L}$ injections and a $325 \mathrm{LC}$ UV-Vis detector was used for 
the analysis of several substrates. Isocratic elution with a solvent mixture of $50 \%$ acetonitrile and $50 \%$ water at a flow rate of $1.00 \mathrm{~mL} \cdot \mathrm{min}^{-1}$ was used for the analysis of SMX. For phenols, a solvent mixture of $50 \%$ acetonitrile ( 0.1 formic) and $50 \%$ water $\left(0.1\right.$ formic) at a flow rate of $1.25 \mathrm{~mL} \cdot \mathrm{min}^{-1}$ was used, and for atrazine a solvent mixture of $65 \%$ acetonitrile $(0.1$ formic) and $35 \%$ water ( 0.1 formic) at a flow rate of $1.00 \mathrm{~mL} \cdot \mathrm{min}^{-1}$ was used. The wavelength of detection was 270,254 and $220 \mathrm{~nm}$ for SMX, phenols and atrazine, respectively. Coliform estimation: Total coliforms and E. coli counts were estimated by the Colilert tray method, which is widely employed in water monitoring. This process used trays and procedures from IDEXX Corporation for the Quanti Tray $/ 2000^{\circledR}$ system. The most probable numbers (MPN) of colonies were estimated with the IDEXX MNP estimator.

\subsection{Pulse and Stored Electron Studies}

A series of experiments were performed to investigate the effect of the pulsed illumination. A locally fabricated programmable controller was used if a light pulse frequency from 1 to 999 ms was required; otherwise, manual off/on was used to achieve pulsing. For fast pulsing, illumination (on) and dark (off) periods in the 200-990-ms range and duty cycles of 10, 30 and 50\% were used.

For stored electron measurements, a sample of $0.02 \mathrm{~g}\left(\mathrm{WO}_{3} / \mathrm{TiO}_{2}\right)$ plus $2 \mathrm{~mL}$ of $33 \mathrm{ppm}$ 4-chlorophenol (4-CP) was irradiated for a chosen time. At that time, $2 \mathrm{~mL}$ iron(III) perchlorate $\left(1 \times 10^{-3} \mathrm{M}\right)$ is added. Then, $1.0 \mathrm{~mL}$ to $1.0 \mathrm{~mL}$ acetate/acetic acid buffer $(\mathrm{pH}=5.5), 0.5 \mathrm{~mL}$ ammonium fluoride $(0.1 \mathrm{M})$ plus $0.5 \mathrm{~mL}$ 1,10-phenanthroline $(0.1 \mathrm{M})$ are added. The number of electrons stored is calculated based on the absorbance of iron(II) phenanthroline at $510 \mathrm{~nm}[11]$.

\section{Conclusions}

The purpose of this study was to explore the relationship of "A/S" and "electron transfer" mechanisms to improve the efficiency of the degradation of organic compounds using three classes of photocatalysts: zeolite- $\mathrm{TiO}_{2}, \mathrm{WO}_{3}-\mathrm{TiO}_{2}$ and carbon- $\mathrm{TiO}_{2}$. The choice was dictated by the aim of comparing two cases, where only one of the mechanisms could be operative, to a case where both might compete. The specific mechanism for the zeolite is $\mathrm{A} / \mathrm{S}$, where $\mathrm{WO}_{3}-\mathrm{TiO}_{2}$ has identified electron transfer with little difference in surface properties between the two components of the composite. Both $\mathrm{A} / \mathrm{S}$ and electron transfer can contribute to carbon- $\mathrm{TiO}_{2}$ systems.

The A/S mechanism must balance adsorption with surface mobility to complete substrate delivery to $\mathrm{TiO}_{2}$. When these two balance, gains can be disappointing, but the present results also show that it is important to monitor surface concentrations to avoid misleading evidence of "enhancement" from solution-only data.

Electron transfer has been confirmed to be contributed to by carbon. In the case of the carbon forms tested here, the gains are minimal. Only small improvement was observed in the case of SWCNTs, and the effect of carbon was detrimental in the case of using AC. This indicates slow surface diffusions, which can even overcome the effect of electron transfer and reduced recombination. However, some degree of limitation may reflect the absence of a relatively stable site for the transferred electron. Pulse experiments indicated short electron storage lifetimes. The long storage lifetime in $\mathrm{WO}_{3}$ illustrates the desired condition, a stabilized electron site analogous to $\mathrm{W}(\mathrm{V})$. 


\section{Acknowledgments}

The financial support of the Natural Sciences and Engineering Research Council of Canada is gratefully acknowledged. This support was part of a strategic research network, RES'EAU Waternet. (This project has terminated, and funds are no longer available to support open access publication). Emad Radwan Hafez thanks the government of Egypt for support.

\section{Author Contributions}

C.L. and G.A. developed the project and the outline of the research. E.R. and M.I. conducted the experimental studies reported. All authors contributed to interpretation and writing. C.L. was responsible for final editing of the manuscript with valuable help from E.R.

\section{Conflicts of Interest}

The authors declare no conflict of interest. The sponsors had no role in study design, data collection analysis or interpretation, writing of the manuscript or the decision to publish.

\section{References}

1. Torimoto, T.; Ito, S.; Kuwabata, S.; Yoneyama, H. Effects of adsorbents used as supports for titanium dioxide loading on photocatalytic degradation of propyzamide. Environ. Sci. Technol. 1996, 30, 1275-1281.

2. Lepore, G.P.; Pant, B.C.; Langford, C.H. Limiting quantum yield measurements for the disappearance of 1-propanol and propanal: An oxidative reaction study employing a $\mathrm{TiO}_{2}$ based photoreactor. Can. J. Chem. 1993, 71, 2051-2059.

3. Colombo, D.P.; Bowman, R.M. Does interfacial charge transfer compete with charge carrier recombination? A femtosecond diffuse reflectance investigation of $\mathrm{TiO}_{2}$ nanoparticles. J. Phys. Chem. 1996, 100, 18445-18449.

4. Takeda, N.; Ohtani, M.; Torimoto, T.; Kuwabata, S.; Yoneyama, H. Evaluation of diffusibility of adsorbed propionaldehyde on titanium dioxide-loaded adsorbent photocatalyst films from its photodecomposition rate. J. Phys. Chem. B 1997, 101, 2644-2649.

5. Vaisman, E.; Kabir, M.F.; Kantzas, A.; Langford, C.H. A fluidized bed photoreactor exploiting a supported photocatalyst with adsorption pre-concentration capacity. J. Appl. Electrochem. 2005, 35, 675-681.

6. Tatsuma, T.; Saitoh, S.; Ngaotrakanwiwat, P.; Ohko, Y.; Fujishima, A. Energy storage of $\mathrm{TiO}_{2}-\mathrm{WO}_{3}$ photocatalysis systems in the gas phase. Langmuir 2002, 18, 7777-7779.

7. Tatsuma, T.; Takeda, S.; Saitoh, S.; Ohko, Y.; Fujishima, A. Bactericidal effect of an energy storage tion-wo3 photocatalyst in dark. Electrochem. Commun. 2003, 5, 793-796.

8. Kedem, S.; Rozen, D.; Cohen, Y.; Paz, Y. Enhanced stability effect in composite polymeric nanofibers containing titanium dioxide and carbon nanotubes. J. Phys. Chem. C 2009, 113, 14893-14899.

9. $\mathrm{Xu}, \mathrm{Y}$;; Langford, C.H. Uv- or visible-light-induced degradation of $\mathrm{X} 3 \mathrm{~B}$ on $\mathrm{TiO}_{2}$ nanoparticles: The influence of adsorption. Langmuir 2001, 17, 897-902. 
10. McMurray, T.A.; Dunlop, P.S.M.; Byrne, J.A. The photocatalytic degradation of atrazine on nanoparticulate tioz films. J. Photochem. Photobiol. A Chem. 2006, 182, 43-51.

11. Zhao, D.; Chen, C.; Yu, C.; Ma, W.; Zhao, J. Photoinduced electron storage in $\mathrm{WO}_{3} / \mathrm{TiO}_{2}$ nanohybrid material in the presence of oxygen and postirradiated reduction of heavy metal ions. J. Phys. Chem. C 2009, 113, 13160-13165.

12. Yao, Y.; Li, G.; Ciston, S.; Lueptow, R.M.; Gray, K.A. Photoreactive $\mathrm{TiO}_{2} /$ carbon nanotube composites: Synthesis and reactivity. Environ. Sci. Technol. 2008, 42, 4952-4957.

13. Sczechowski, J.G.; Koval, C.A.; Noble, R.D. Evidence of critical illumination and dark recovery times for increasing the photoefficiency of aqueous heterogeneous photocatalysis. J. Photochem. Photobiol. A Chem. 1993, 74, 273-278.

14. Yu, L.; Achari, G.; Langford, C. Led-based photocatalytic treatment of pesticides and chlorophenols. J. Environ. Eng. 2013, 139, 1146-1151.

Sample Availability: Samples of the compounds are available from the authors.

(C) 2014 by the authors; licensee MDPI, Basel, Switzerland. This article is an open access article distributed under the terms and conditions of the Creative Commons Attribution license (http://creativecommons.org/licenses/by/4.0/). 